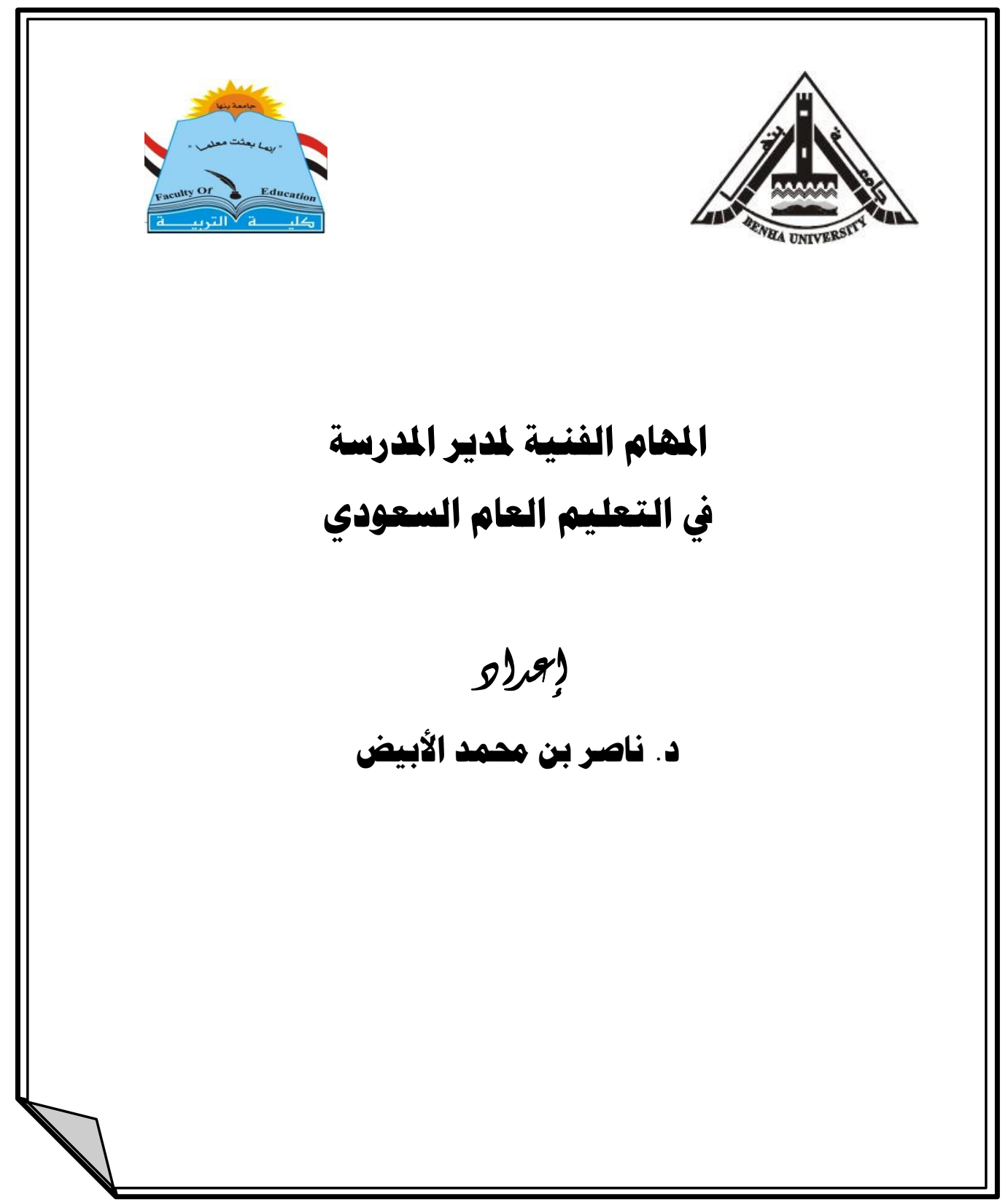




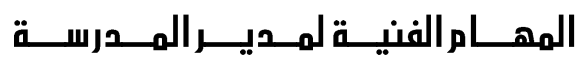

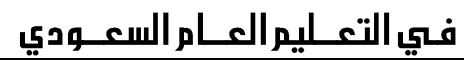

\section{المهام الفنية لمدير المدربسة في التعليم العام السعودي}

\section{8) ?}

\section{د. ناصر بن هممد الأبيض}

الاقدهمة

في زمنٍ تعقدت فيه الوظائف ، وأضحى تطورها بوتيرةٍ منسارعةٍ جدًا ، ورغم التوجهات الرسمية على كافة المستويات التشريعية والتكتيكية والتتفيذية ؛ الرامية إلى الارتقاء بأداء مدير المدرسة في مراحل التعليم العام ؛ إلا أن دور القائد التربوي الذي

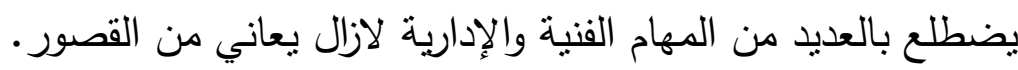
لقد توجهت أنظار المسؤولين بوزارة التربية والتعليم نحو مدير المدرسة بوصفه مشرفًا تربويَّا مقيمًا، يجب عليه أن يقوم بدورٍ فنيٍِ ينعكس إيجابًا على تحقيق أهداف

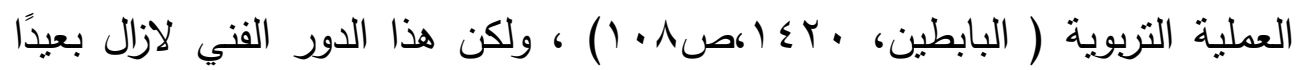
عن المستوى المأمول إلى حدٍ يحتاج إلى وقفةٍ ومراجعةٍ واستخدام أساليب البحث العلمي للكثف عن المعوقات التي تقف في سبيل تحقيق هذا الدور لأهدافه . وحسب العديد من الدراسات العربية والأجنبية التي تظهر تمركز جهود مديري المدارس حول المهام الإدارية على حساب المهام الفنية ، حيث تراوحت نسبة الوقت

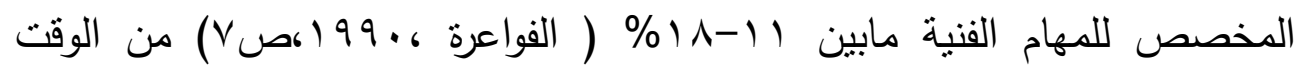
الكلي الذي يقضيه مدير المدرسة في يوم عمل واحد ، وهذا مؤشر خطير يدل على عدم تحقيق التوازن النسبي المطلوب مابين المهام الرئيسة لمدير المدرسة في التعليم العام بثقيها الفني والإداري - التماي وقد توخت هذه الدراسة أن تلقي الضوء في إطار التوجهات الحديثة للمبدان التربوي على المهام الفنية لمدير المدرسة في التعليم العام لتحقق بذلك خطوة نحو التوازن 
النسبي المأمول مابين المهام الإدارية والفنية في مجالات تتعلق بتحسين عملية التعلم والتعليم للطلاب ، والتتمية المهنية للمعلمين ، والتواصل مع المجتمع المحلي •

\section{مشكلة الندراسة}

رغم الجهود التي تبذلها الجهات الرسمية المسؤولة عن إدارة التعليم العام بدءًا

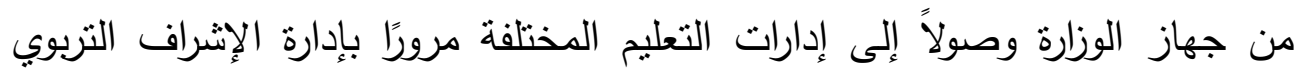

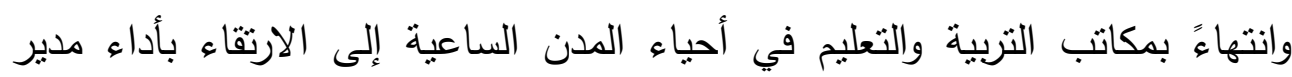
المدرسة المتضمن لأداور متوازنةٍ توازنًا نسبيًا ؛ إلا أن الجانب الفني لازال يمنل الكفة المرجوحة في ميزان المهام في مقابل كفة الجانب الإداري الراجحة . إن الجانب الفني يعتبر الأكثر أهمية- رغم واقعه غير المرضي - من الجانب الإداري الذي يستولي على جل وقت مدير المدرسة ( الفواعرة، ، ،99 (،صلع)، وفي الجهة المقابلة فإن الدور الفني للمشرف التربوي محدود الأثر ، من ذلك أن أحد التعاميم الصادر عن إدارة التربية والتعليم في الرياض يتضمن توجيهًا للمشرفين التربويين بضرورة زيارة المعلمين الذين مرَّ عليهم خمس سنوات دون زيارة ، وهنا دلالة كبيرة على القصور الذي يمكن لمدير المدرسة أن يعمل على استكماله .

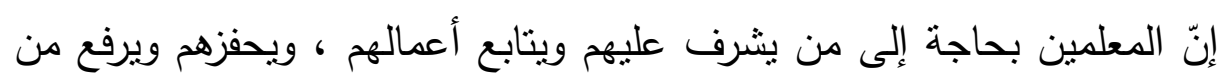
كفاءاتهم ، وكل ذلك يمكن أن يقوم به مدير المدرسة بتواجده الدائم فيها(المنيف، • ( ( اصل • () فلا يمكن بأي حال من الأحوال أن نغفل عن أن مدير المدرسة أكثر إلمامًا بإمكانات المدرسة وظروف الطلبة والمعلمين والمجتمع المحلي •

\section{أهداف الدوراسة}

$$
\text { هدفت هذه الدراسة إلى التعرف على : }
$$

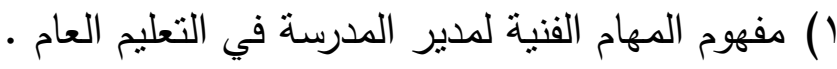

r) مجالات أداء المهام الفنية لمدير المدرسة في التعليم العام •

ץ) معوقات أداء المهام الفنية لمدير المدرسة في التعليم العام • 


\section{أهمية الدراسة}

برزت أهمية الدراسة من أهمية الدور القيادي الذي يضطلع به مدير المدرسة

في التعليم العام ، ومن المؤمّل أن تسهم هذه الدارسة في تحقيق الفوائد الثالية :

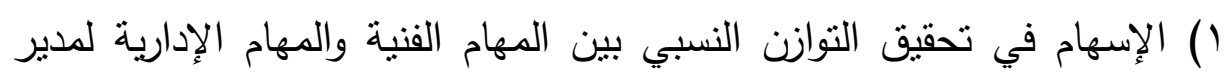

$$
\text { المدرسة . الإسهام }
$$

r) الإسهام في تحقيق تكامل الأدوار بين المشرف التربوي ومدير المدرسة .

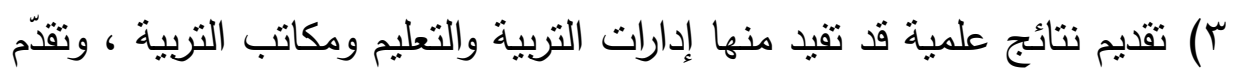
على هيئة نشرات تربوية أو أوراق عمل خلال الاجتماعات الدورية التي تقام

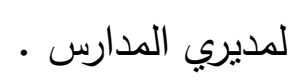

أسئلة الدراسة

هدفت هذه الدراسة إلى الإجابة عن الأسئلة التالية :

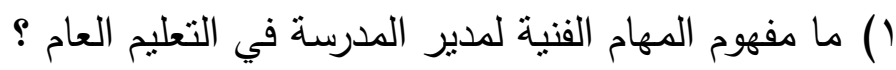

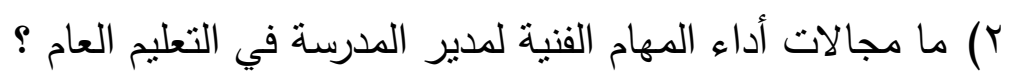

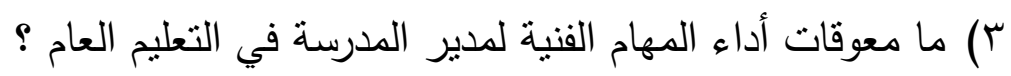

\section{مدود الدراسة}

اقتصرت هذه الدراسة على المهام الفنية ومجالات الأداء ومعوقاته لمدير

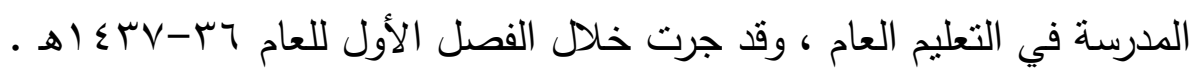

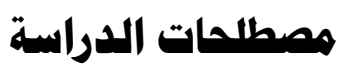

المهام الفنية : المقصود بها الوظائف والواجبات المرتبطة بتغيير سلوك المنتسبين

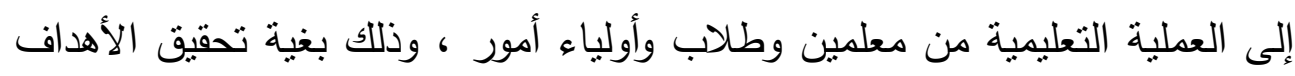

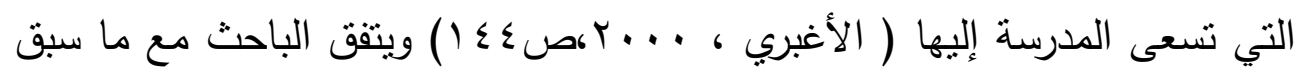

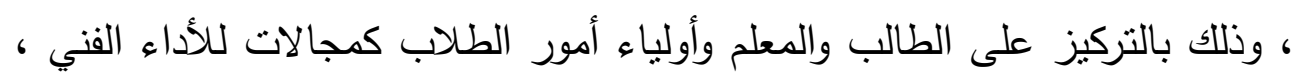


مع تتاول المجال الثالث في هذه الدراسة كمفهوم أوسع وأكثر شمولية بإضافة

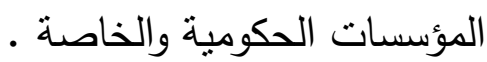

مدير المدرسة : هو المسؤول الأول في المدرسة ، وهو المشرف على جميع شؤونها

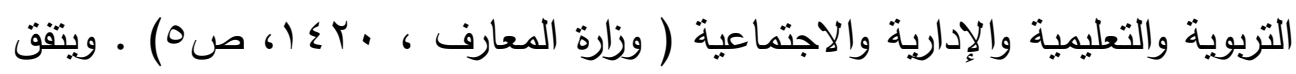

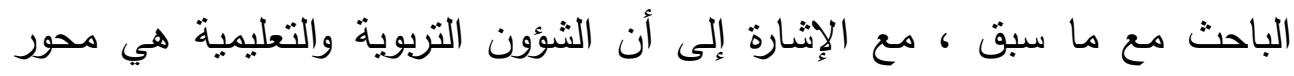

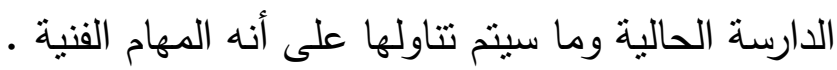
التعليم العام : هو التعليم الذي يضم ثلاث مراحل دراسية ، تمنل في مجموعها سلم

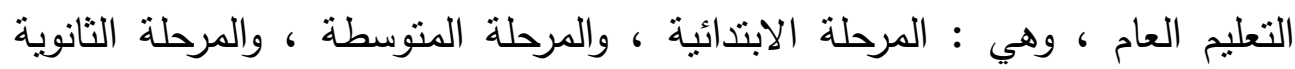

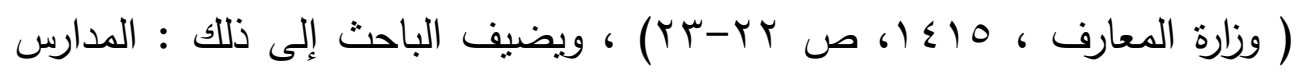

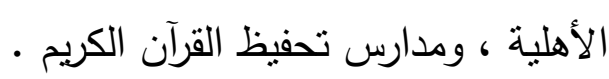

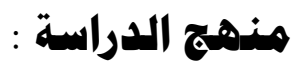

اتبّع الباحث في دراسته أسلوب المنهج الوصفي المكتبي ، وذلك بالعودة إلى

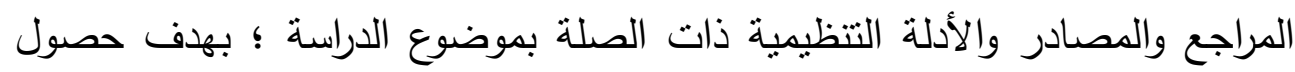

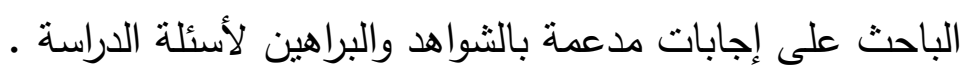

\section{الإطـار النظـري}

\section{مفهوم المهام الفنية لمدير المدرسة}

قبل الحديث عن المهام الفنبة لمدير المدرسة ، تجدر الإثارة السريعة إلى الى

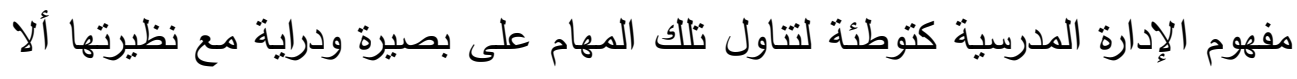
وهي المهام الإدارية. وقد تعددت الآراء واختلفت وجهات النظر حول تحديد مفهوم الإدارة المدرسية

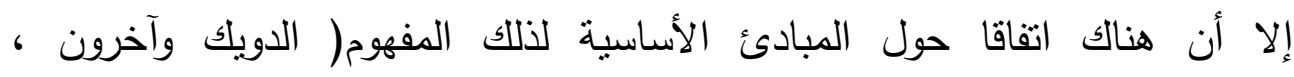

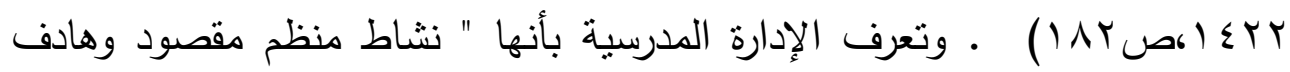




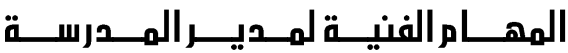

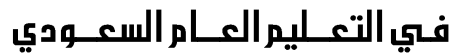

تحقق من ورائه المدرسة الأهداف التربوية المنشودة " ( سمعان ومرسي ،

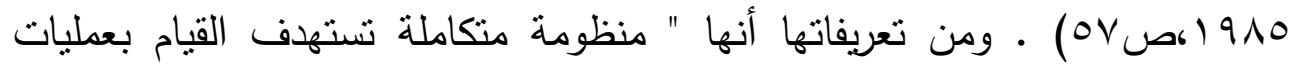
تخطيط وتسيير وتقويم الموارد البشرية والمادية المتاحة للمدرسة ، والتوصل إلى مجموعة القرارات التي يؤدي تطبيقها إلى تحقيق الأهداف المرجوة بفعالية " ( زاهر ، 1990،صYr|) - وفي تعريف آخر هي الجهود المنسقة التي يقوم بها فريق من العاملين في المدرسة سواء أكانوا إداريين أم فنبين ، بغية تحقيق الأهداف التربوية

داخل المدرسة تحقيقا يتماشى مع ما تهدف إليه الدولة ( أحمد ، سبـ (،صى1) . ونظرا لتطور مفهوم الإدارة المدرسية وتعقدّه ؛ حيث أصبح يضم العديد من

المهام منها ما هو إداري ومنها ما هو فني ، ولانتقال محور عمل مدير المدرسة من الثؤون الإدارية الصرفة إلى إعطاء الموارد البشرية طلابا ومعلمين ومجتمعا محليا قدرا مناسبا من الاهتمام ، من هنا ييرز دور مدير المدرسة في العمل على تحقيق التوازن النسبي مابين تلك المهام الإدارية والفنية ، ليصل إلى أعلى درجات الأداء

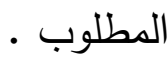

ومن المناسب هنا أن يتتاول الباحث المهام بنوعيها بشيء من التعريف ،

قبل أن يبين العوامل التي تحتم على مدير المدرسة أن يولي المهام الفنية قدرها اللازم من الوقت والاهتمام والعناية .

ولنبدأ بالمهام الإدارية فهي " جميع المهام والواجبات التي ينبغي لمدير المدرسة القيام بها ، لضمان سير العمل بيسر وسهولة " ( الأغبري ، ... . . .

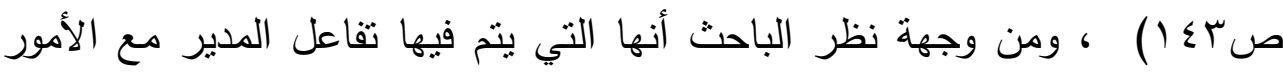
المادية أكثر من الموارد البشرية ، وفي دراسة أجريت للتعرف على تلك المهام تم عرض بعضها كما يلي : ( ) الاهتمام بالمبنى المدرسي وصيانة مرفقاته . r) الإشراف على ضبط دوام المنتسبين للمدرسة من طلاب ومعلمين وإداريين. 


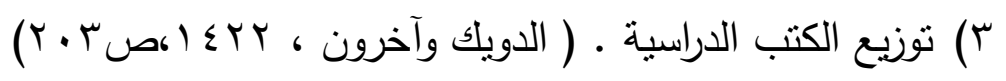

ع) العناية بتوفير ومتابعة صرف خطة المدرسة من الوسائل التعليمية . 0) إعداد الخطة التشغيلية والموازنة السنوية للمدرسة . T) إعداد الجداول المدرسية ، وتوزيع المهام على العاملين بعدالة .

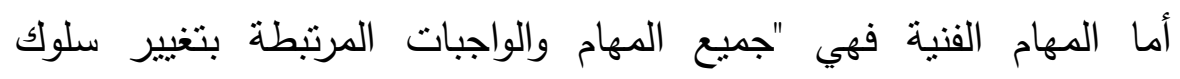
المنتسبين إلى العملية التعليمية من معلمين وطلاب وأولياء أمور ، وذلك بغية تحقيق

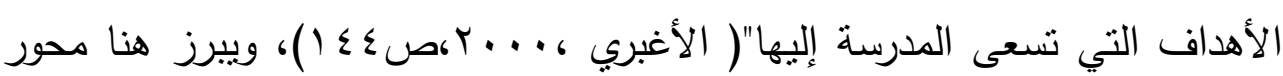
الدراسة الحالية وتقلها الأكبر ، وتتسجم كل من المهام الإدارية الفنية والمهام الإدارية في علاقة تكاملية ، يصعب معها الفصل الواضح بين كل منهما ـ

ومن المناسب في هذا المقام ذكر العوامل التي تحتم إيلاء مدير المدرسة المهام الفنية حقها من الاهتمام اللزم ، وهي : ( ) انتقال محور العملية التربوية إلى الطالب، وهذا ما يحتم على مدير المدرسة

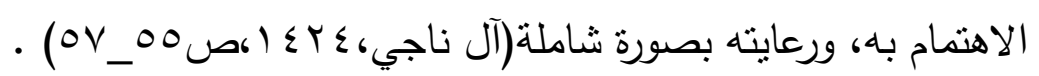

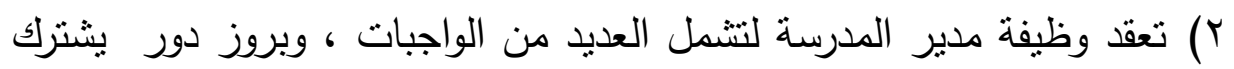
فيه مدير المدرسة مع المشرف التربوي ، ألا وهو دور التتمية المهنية للمعلمين وتطور أدائهم ؛ وهو دور فني بحت . r) النظر إلى النظام التعليمي على أنه نظام مفتوح، يؤثز في البيئة الخارجية بنفس الدرجة التي يتأثز بها وهو ما يسمى بالمجتمع المحلي(آل

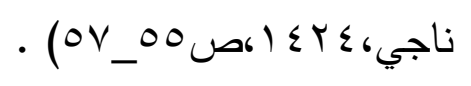


مجالات أداء المهام القنية لمدير المدرسة أ-الطالب :

نظرا لتطور مفهوم التربية وانتقال محور الاهتمام إلى الطالب وتتميته من جميع الجوانب العقلية والنفسية والاجتماعية والجسمية ، فإن الإدارة المدرسية لزامًا ستوجه إسه جهودها نحو رعايته والعناية به ، وفيما يأتي عرض لأهم المهام الفنية التي يضطلع بها مدير المدرسة نحو الطالب : الوقوف على حاجات الطلاب ، و مراعاة الفروق الفردية بينهخ • دراسة مشكلات الطلاب ، والوقوف على أسبابها ، والعمل على إيجاد الحلول المناسب لها

تقويم الطلاب ، وتنخيص مواطن القوة لتعزيزيها و الضعف لعلاجها . استثمار قدرات الطلاب و استعداداتهم ، وصقل مواهبهم ، وتمكينهم من هواياتهم توفير الظروف والأجواء المساعدة على عمليتي التعليم والتعلم ، والحياة الديموقراطية للطلاب ( الخطيب وآخرون ، بـ ( كص 109) .

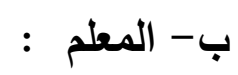

إن التتمية المهنية للمعلمين ، وجودة توجيه قدراتهم ، وحسن التعامل معهم، على اعتبارهم خط المواجهة الأمامي المباشر الذي يعمل على تحقيق أهداف النظام التعليمي والتربوي ، كل ذللك يمنل مهام حساسة ، بالغة الأهمية والأثز ، ومجالا رحبا

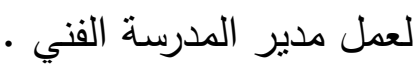
وفيما يلي عرض لأهم المهام الفنية التي يفترض بمدير المدرسة الناجح القيام

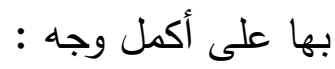


عقد المجالس الفنية مع المعلمين عامةً ، وعلى وجه الخصوص معهم حسب تخصصاتهم ومراحل تدريسهم لمناقشة الأهداف التعليمية ومحتويات المناهج وطرق التدريس والوسائل التعليمية اللازمة .

الاطلاع المستمر على الأداء الفعلي للمعلمين داخل الفصول، والمناشط الصفية والأعمال الكتابية : كراسات التحضبر وسجلات التقويم والاختبارات . تشجيع المعلمين على الابتكار والتجديد في طرق التدريس وإنتاج الوسائل التعليمية وأساليب ثقويم الطلاب. تنسيق العمل الفني في المدرسة بين التخصصات المختلفة والمراحل المنباينة من ورش عمل ونماذج دروس ونشرات تربوية وخلافه .( حجي ،

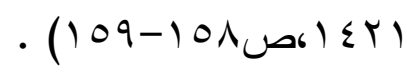

تطوير مهارات المعلمين في الإدارة الصفية ،أما بتدريبهم المباشر من قبله ، أو بتوجيههم إلى زيارة معلم متميز داخل أو خارج المدرسة ، أو باستقطاب المدربين إلى المدرسة ، أو إلحاقهم بما بعقد من دورات على مستوى الإدارة في مراكز التدريب التربوي • العمل التكاملي مع المشرف التربوي للخروج بعمل منظم وهادف ، بغية الرفع من أداء المعلمين الصفي وتتميتهم مهنيًا وتطوير مهاراتهم الفنية . توجيه المعلمين إلى مصادر المعرفة المختلفة من مراجع تربوية ومراكز بحثية

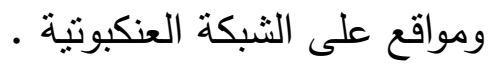

متابعة انتقال أثر التدريب التربوي والبرامج التعليمية والأساليب الإشرافية . ج- المجتمع المحلي : بما أن المدرسة تعمل في نظام مفتوح يؤثز ويتأثز بالبيئة الداخلية من منسوبي المدرسة من الطلاب والمعلمين والموظفين ، والبيئة الخارجية من أولياء أمور الطلاب لئب والجهات الإشرافية والمؤسسات الحكومية والخاصة ومؤسسات المجتمع المدني ، لذلك 
كان التعامل مع هذه الأطراف الداخلية والخارجية مهمًا للغاية كمهمة فنية يضطلع بها

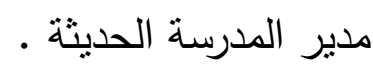

هنا يبرز القائد التربوي في خلق جو أسري بين منسوبي المدرسة ، مع التركيز على أهمية بناء علاقة بين الطلاب ومعلميهم قائمة على أساس من الاحترام والتقدير والعطف والمودة ، وعلى درجة من الأهمية أن ينتقل نمط العلاقة ليشمل المعلمين

والموظفين فيما بينهم البين .

ولكي لا تكون المدرسة في عزلة عن الجهات الإشرافية ينبغي على مدير المدرسة

الاهتمام بالأمور التالية :

الرد على التعاميم ، وتقديم البيانات الدقيقة والحديثة عن واقع المدرسة ، والعمل بما يرد من توجيهات صادرة عن الجهات الإشرافية على شتى مستوياتها تسهيل مهام المشرفين التربوبين ، وحسن التعامل وبناء علاقة إيجابية وبناءة معهم ؛ لما فيه تحقيق المصلحة العامة للمدرسة . الحرص على حضور الاجتماعات والورش التربوية التي تعقدها الجهات الإشرافية ، وتفعيل ما يقدم فيها من توجيهات وتوصيات لتصبح واقعا ملموسا • في الميدان التربوي وتتجلى أبرز المهام التي يضطلع بها مدير المدرسة في مجال المجتمع المحلي (البيئة الخارجية ) فيما يلي : إقامة المجالس العمومية - مجالس الآباء - في مواعيدها المحددة ، وتعربف أولياء أمور الطلاب ببرامج المدرسة وأنشطتها، وتشجيعهم على زيارة المدرسة التهاء

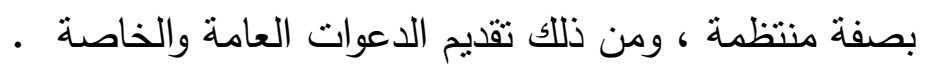
تأسيس ثقافة العمل التطوعي لخدمة الحي ومرافقه العامة .

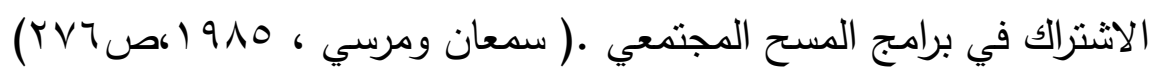


تزويد الصحف المحلية والمواقع الإلكترونية والمنتديات التعليمية بالبرامج

$$
\text { والأنشطة والإنجازات المدرسية . }
$$

الإفادة من الثبكة العنكبوتية بتأسيس موقع المدرسة وتقديم خدمات القبول والتسجيل وتعريف الأسرة بمستوى التحصيل الدراسي لأبنائهم ، وفتح المجال للالتحاق بالبرامج والأنشطة إلكترونيا ، وإتاحة الفرصة للنقاش والنقد البناء الهادف لتحسين الأداء التعليمي والإداري من خلال تلقي المقترحات والثكاوي سواء بالرسائل الخاصة أو عن طريق المنتديات العامة . تأسيس لجنة العلاقات العامة بالمدرسة ، وإعطاؤها الاهتمام المناسب ومن ذللك رئاسة مدير المدرسة لها ، وعضوية الوكلاء ، وتمثيل عدد من المعلمين بناء على الكفاءة والقدرة والرغبة ، حتى تكون على المستوى المطلوب في الأداء والعطاء . أهـ المشاركة في المناسبات الدينية والوطنية والاجتماعية ، كالمعايدات والأسابيع والأيام الخاصة : اليوم الوطني ، الإنجازات الوطنية ، أسابيع المرور والثجرة والمهنة ... وأكثر من ذلك المشاركة في تهنئة أسر الحي ومواساتهم في أحزانهم ، وتلمس احتياجاتهم المختلفة . واند إقامة وتبني ودعم الاحتفالات والمعارض لمنسوبي المدرسة وأهالي الحي على ولى حدٍ سواء .

وضع صندوق للثكاوي والاقتراحات ، والعناية بما برد من منسوبي البيئة

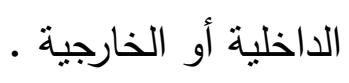

معوقات أداء المهام القتية لمدير المدرسة نظر الباحث إلى هذه المعوقات من أربع زوايا : الأولى : معوقات متعلقة بطبيعة المهمة : فالملاحظ أن كثير من مديري المدارس

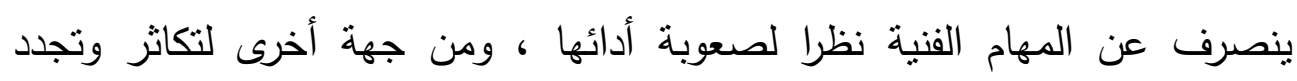


الأعمال الإدارية التي تكون بتكليف من الجهات الإشرافية ، وتتم المسائلة والمحاسبة على أدائها بصفة مباشرة وسريعة لسهولة ضبطها ومتابعتها . الثانية : معوقات متعلقة بالمدرسة : وتتمنل في الكادر الإداري والفني وضعفه على ملى مستوى الأداء وقبل ذلك وجود خلل على مستوى التوافر ، وقلة الإمكانات المادية المدرسية المعينة على القيام بالمهام الفنية كقاعات التدريب و المعامل والمسارح والوسائل التعليمية ووسائل الاتصال وشبكة المعلومات . الثالثة : معوقات متعلقة بمدير المدرسة: وذللك بسبب الإغراق في النمطية وعدم الرغبة في التجديد ، كون المهام الفنية تمثل تحديًّا وعملاً غير تقليدي يحتاج لإعمال فكر وإبداع ، ويتم تأديته عن طريق العقل الواعي ، بينما المهام الإدارية تحمل الطابع الروتيني البحت ، ويتم تأديتها عن طريق العقل اللا واعي • الرابعة : معوقات متعلقة بمجالات الأداء : أ- الطالب : وثبرز في هذا المجال المعوقات التالية : ضعف دافعية الطلاب للتعلم والتعليم . صن تدني رضا الطلاب عن واقعهم التربوي والتعليمي • ضعف تقاعل الطلاب الصفي . زيادة عدد الطلاب في حجرة الصف الدراسي الواحد . ارتفاع نسبة الهدر : التأخر ، الرسوب ، التسرب( العارفة وقرّان

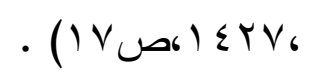

ب- المعلم : وتبرز في هذا المجال المعوقات التالية : صعوبة الإشراف على معلمين من مختلف التخصصات ، وتتميتهم مهنيًا في ضوء إعداد مدير المدرسة الأكاديمي الذي تلقاه. الاعتقاد السائد بتعارض دور مدير المدرسة مع دور المشرف التربوي ( عبديد

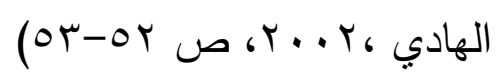


عزوف المعلم عن تطوير ذاته مهنيا ، ومرد ذلك عدم ربط التطوير المهني بامتيازات معنوبة مؤثرة أو حوافز مادية مجزبة . عدم قدرة المعلم على توظيف التقنيات الحديثة في التدريس ، وقلة إلمامه بأدوات التقويم وأساليبه ، وضعف مهاراته في الاتصال الفعال مع الطلاب . تدني مستوى الرضا الوظيفي لدى المعلم السعودي. ( العارفة وقرّان

$$
\left(I V^{\prime} v_{6}\right) \leqslant r V_{6}
$$

ج- المجتمع المحلي : وتبرز في هذا المجال المعوقات التالية : ضعف حضور أولياء أمور الطلاب للمجالس العمومية ، وغياب دورهم الإيجابي في التواصل مع المدرسة فيما يتعلق بشؤون التحصيل الدراسي لأبنائهم ، فضلا عن الأنشطة والبرامج والاحتفالات والمعارض والمناسبات .

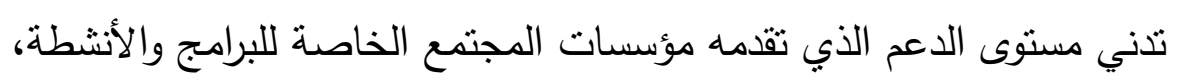
وتخليها عن تحمل مسؤوليتها الاجتماعية . قصور ثقافة العمل التطوعي ، وتعاون أفراد المجتمع في تعزيز السلوك

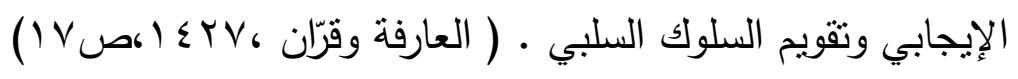
قصور إيمان مدير المدرسة بدوره الريادي والضروري والأساسي في هذا

$$
\text { المجال واعتبار كل ذلك من الترف التربوي • }
$$

\section{الاراسات السابقة}

القسم الأول : الدراسات المتعلقة بمفهوم المهام القنية

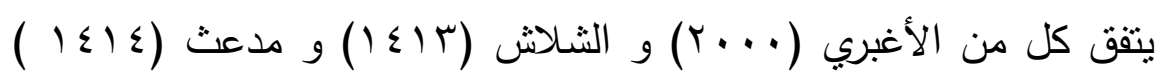
والثهري (•r ( ) في تصنيف المهام إلى : إدارية وفنية . ويختلف معهم كل من العدوش (99v (199) حيث أضاف إلى المهام الإدارية والفنية المهام المالية ، والثامخ

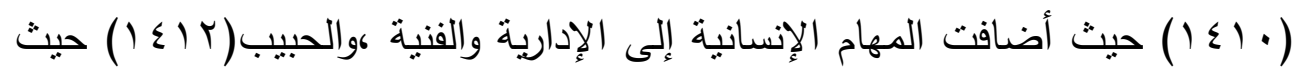




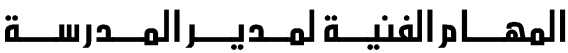

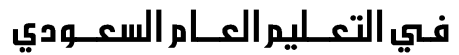

أضاف المهام الاجتماعية ـ والباحث يذهب إلى تصنيف المهام إلى إدارية وفنية ؛ حيث إنه من المنطقي أن تدرج المالية تحت المهام الإدارية ، أما الإنسانية والاجتماعية فتدرج تحت المهام الفنية .

أما بالنسبة للقول بغلبة المهام الإدارية على المهام الفنية في عمل مدير

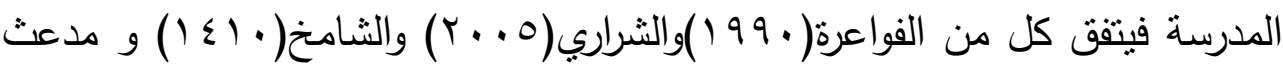

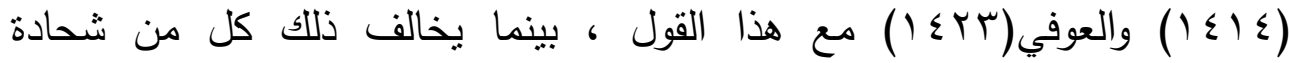

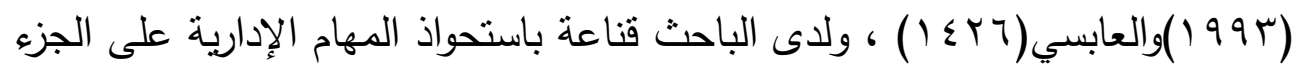
الأكبر من عمل مدير المدرسة ، ومرد هذه القناعة إلى العدد الكبير من الدراسات العلمية التي تؤيد ذلك ، والخبرة العملية للباحث.

القسم الثاني : الدراسات المتعلقة بمجالات أداء المهام القنية تتفق جميع الدراسات - حسب إطلاع الباحث - على المجالات الثلاثة : الطالب والمعلم والمجتمع المحلي • ولكن بعضها يضيف إلى ما سبق ما يتعلق بالمهنة كفن وهما :علمية التخطيط وعملية تقويم المناهج • ومن تلك الدراسات دراسة

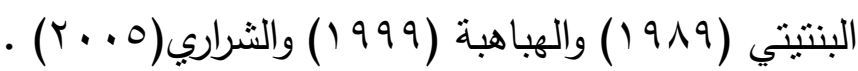
ويوضح الباحث جانب التميز في هذه الدراسة باستهداف مجالات الطالب والمعلم والمجتمع لكونها تمنل ما يسمى برأس المال البشري أو الموارد البشرية ، حيث يزعم الباحث بتقردها من مدرسة إلى أخرى بصورة أكبر من عميلتي التخطيط وتقوبم المناهج ، فهما أقل تفردا لوجود إدارة خاصة بالتخطيط على كافة مستويات الجهات المسؤولة ، ولكون المناهج السعودية موحدة وتقوم عليها إدارة خاصة أيضا ، وهذا ما يستدعي توجيه الباحثين جهودهم إلى الموارد البشرية بصورة أكبر • 
القسم الثالث: الدراسات المتعلقة بمعوقات أداء المهام الفنية

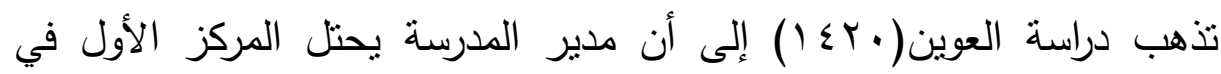
ترتيب المعوقات ، نظرًا لضعف إعداده وتأهيله وتدريبه ، وحسب دربل إطلاع الباحث

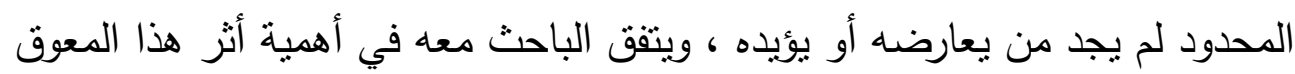

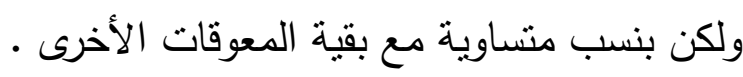

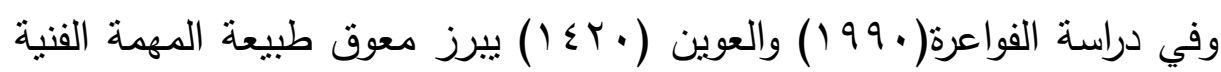

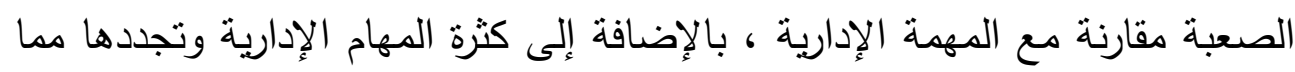

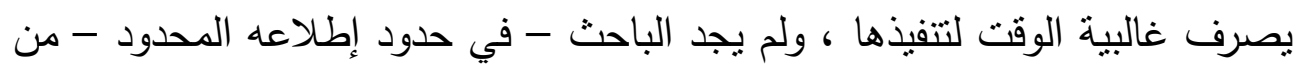
يعارضهما ، ويتفق الباحث معهما .

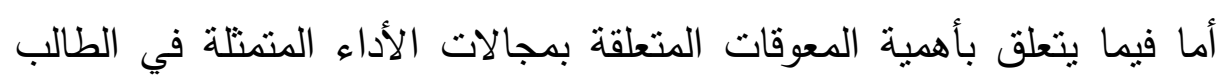

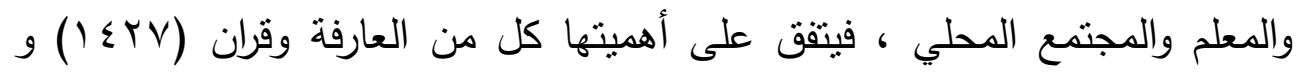

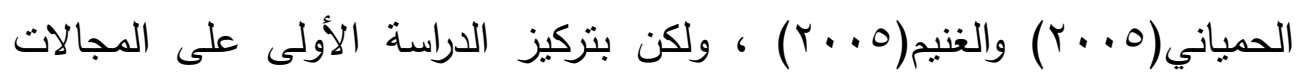

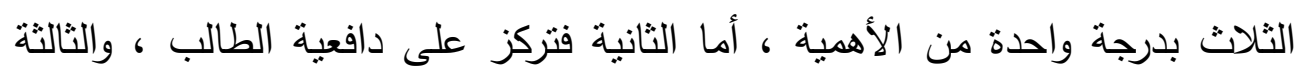

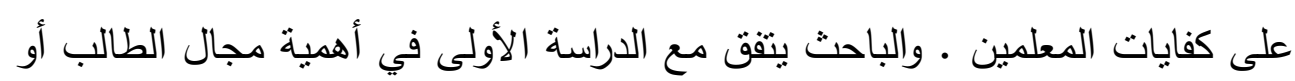

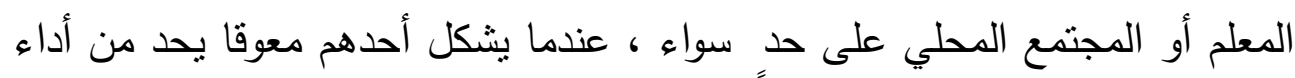

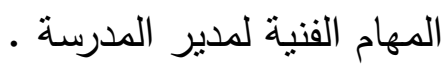




\section{نتائج الدراسة}

إجابة السؤال الأول :ما مفهوم المهام القنية لمدير المدرسة في التعليم العام ؟ للإجابة عن السؤال الأول قدم الباحث مفهوما خاصا للمهام الفنية في ضوء مراجع البحث والدراسات السابقة وهو أنها : الأنشطة الهادفة الموجهة إلى الموارد البشرية في المدرسة والجهات ذات العلاقة خارج المدرسة ، وهذا ما بتقق مع الأغبري ( . . . . . . . إجابة السؤال الثاني :ما مجالات أداء المهام الفنية لمدير المدرسة في التعليم العام ؟ للإجابة عن السؤال الثاني وفي ضوء المفهوم الخاص الذي قدمه الباحث والمتعلق بالمهام الفنية في إجابة السؤال الأول ، فإن المجالات تتحصر في الطالب والمعلم

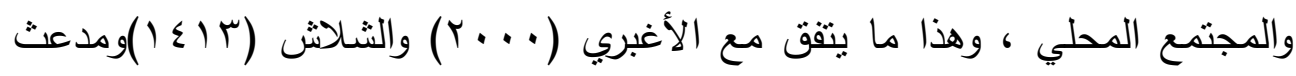

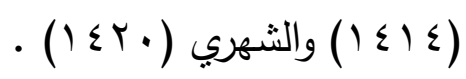

إجابة السؤال الثالث :ما معوقات أداء المهام الفنية لمدير المدرسة في التعليم العام ؟ للإجابة عن السؤال الثالث وفي ضوء المجالات الثناث التي خلص إلبها الباحث في نتيجة السؤال الثاني ، فإن تدني دافعية الطالب ، وهذا ما يتفق مع دراسة

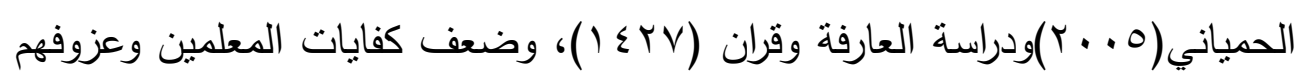
عن تطوير ذواتهم مهنيا ، وهذا ما يتقق مع دراسة الغنيم (0 . ب) ودراسة العارفة

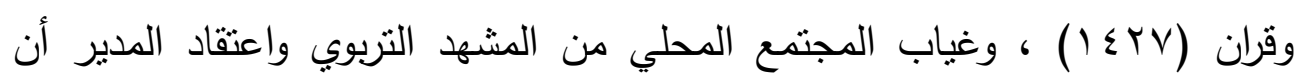
التواصل معه من الترف التربوي ، هي أبرز ما يمكن الإشارة إليه من المعوقات التي من ماني تقف في طريق مدير المدرسة لأداء مهامه الفنية . 


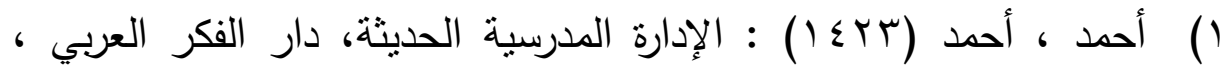

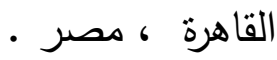

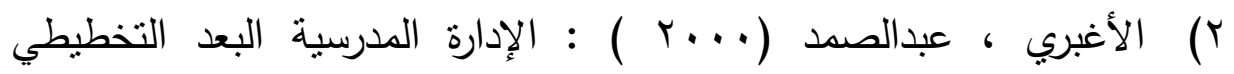

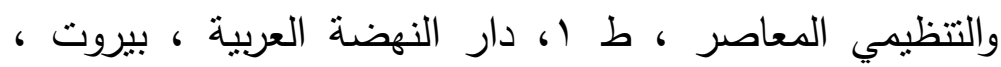

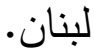

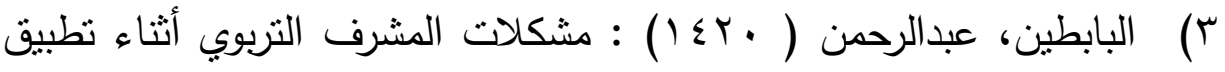
الأساليب الإشرافية ، بحث علمي منشور في رسالة التربية وعلم النفس ، العدد · (1 ، الرياض ، السعودية .

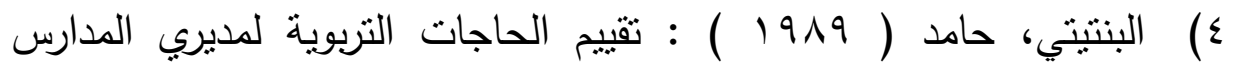

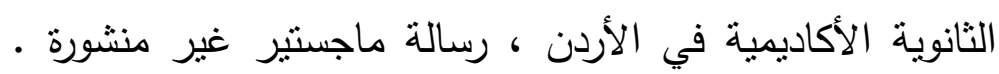

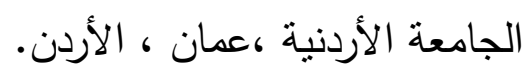

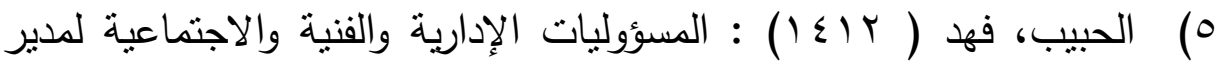

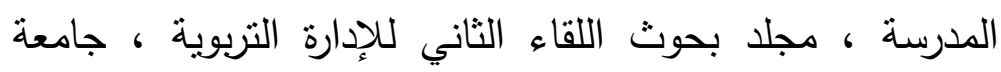
الملك سعود ، كلية التربية ، الرياض ، السعودية .

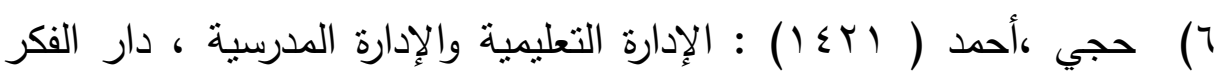

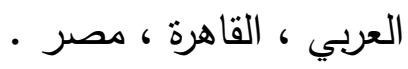

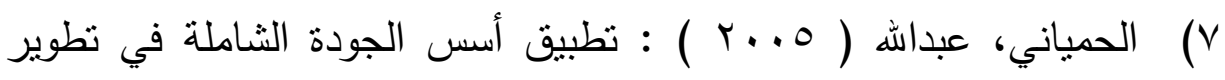

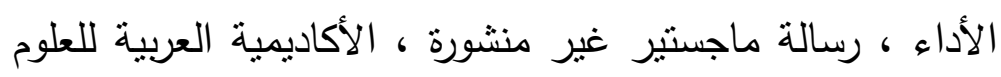

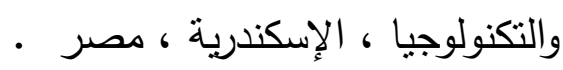

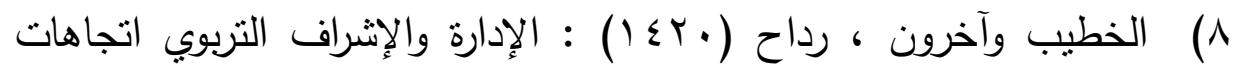

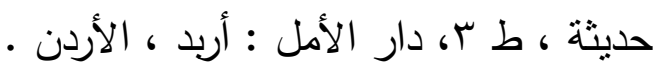


9) الدويكك وآخرون ، تيسير ( r ا I ) ) : أسس الإدارة التربوية والمدرسية

والإشراف التربوي ، ط س ، دار الفكر العربي ، عمان ، الأردن .

• () زاهر ، ضياء ( 1990 ) : الوظائف الحديثة للإدارة المدرسية ، بحث

علمي منشور في رسالة مستقبل التربية ، المجلد ا ، العدد ع .

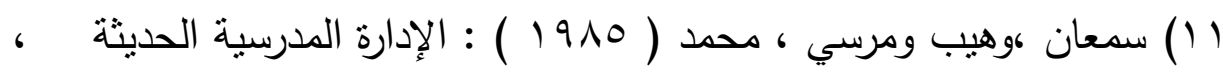

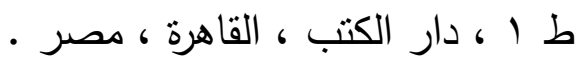

r (1) الثامخ ، هيا ( • ( I ) ) : دور المساعدات في المدارس الثانوية الحكومية للبنات بمدينة الرياض دارسة ميدانية ، رسالة ماجستير غير منشورة ، جامعة الملك سعود ، كلية التربية ، الرياض ، السعودية

r1) شحادة، حسين ( س991 ) : المهام الإدارية والفنية المنوطة بمديري المدارس الثانوية العامة في الأردن ومدى تتفيذهم لها ، رسالة

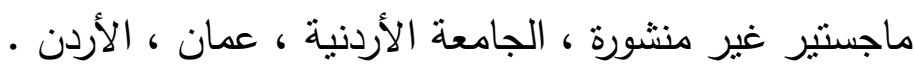
ع () الثراري ، عبدالرحمن ( 0. . F ) : المهام الإدارية والفنية التي يمارسها مديري المدارس العامة بمحافظة القربات من وجهة نظر المعلمين ، رسالة ماجستير غير منشورة ، الجامعة الأردنية ، عمان ،

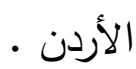

1) الثلاش ، عبدالرحمن ( ساء () : مهام مديري المدارس والموجهين التربوبين بمنطقة الرباض التعليمية دراسة مقارنة ، رسالة ماجستير غير منشورة ، جامعة الملك سعود ، كلية التربية ، الرياض ، السعودية . 


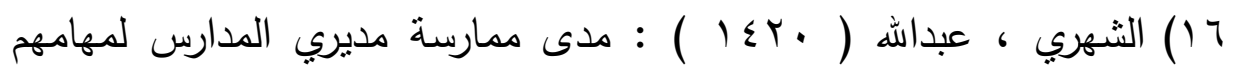
الإشرافية في محافظة بيشة التعليمية ، رسالة ماجستير غير

منشورة ، جامعة الملك سعود ، كلية التربية، الرياض، السعودية .

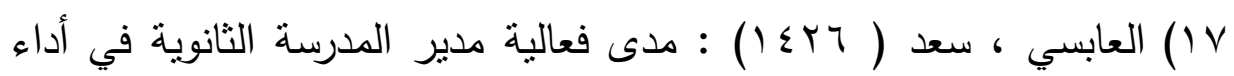
مهامه الفنية دراسة ميدانية في منطقة عسير التعليمية ، رسالة ماجستير غير منشورة ، جامعة الملك سعود ، كلية التربية ، الرياض ، السعودية . ماضية 1 1) العارفة ، عبد اللطيف وقرّان ، أحمد ( I I I ) ) : معوقات تطبيق الجودة في التعليم العام ، مجلد بحوث اللقاء السنوي للجمعية السعودية للعلوم التربوية والنفسية ، الرياض ، السعودية .

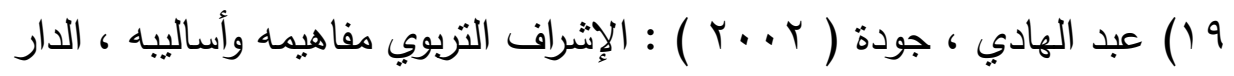

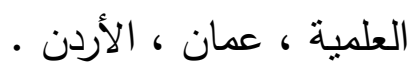
•r) العموش، نايف ( 997 ( ) ) دور برنامج تدريب مديري ومديرات المدارس الأساسية في محافظة المفرق في إكسابهم الكفايات المهنية ،

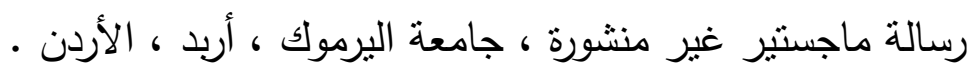
(r) العوفي، أحمد ( r ( ا I ) : التوازن بين المهام الإدارية والفنية لدى مدير المدرسة الثانوية بمحافظة الطائف كما يدركه المعلمون ، رسالة ماجستير غير منشورة ، جامعة أم القرى، مكة المكرمة ، السعودية .

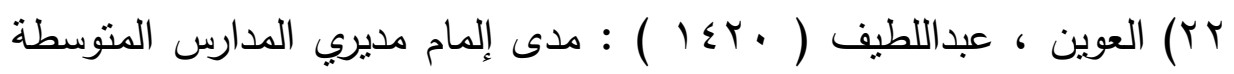
والثانوية في مدينة الرياض بمهامهم الإشرافية والمعوقات التي تحدي منه ، رسالة ماجستير غير منشورة ، جامعة الملك سعود ، كلية التربية ، الرياض ، السعودية . 


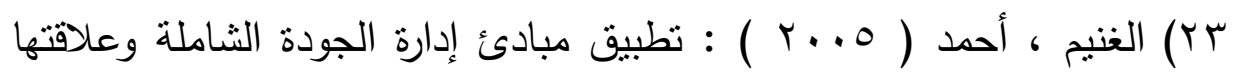
بالكفاية المهنية لدى المعلمين في المدارس الثانوية الحكومية بالمدينة المنورة ، بحث علمي منشور في مجلة جامعة أم القرى ،

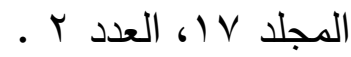

ع r) الفواعرة ، سامي ( .99 ) : دور مدير المدرسة الثانوية كمشرف تزبوي

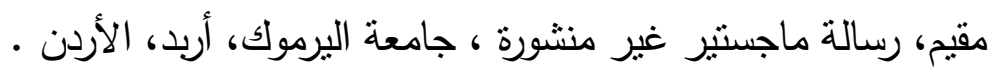

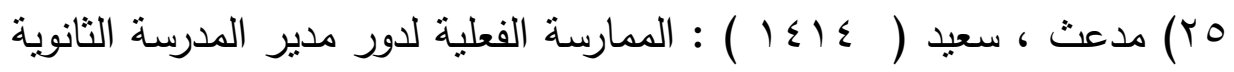
الإداري والفني ، رسالة ماجستير غير منشورة ، جامعة أم القرى ،

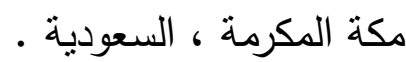
TY) المنيف ، محمد ( · (1) : : دور مدير المدرسة كموجه تربوي مقيم ، مطبعة البيكرية ، الرياض ، السعودية .

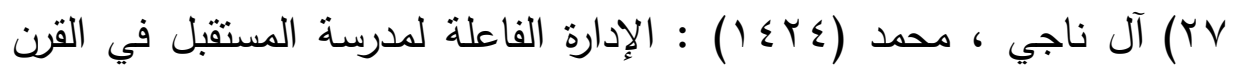
الحادي والعشرين ، مكتبة الرشد ، الرياض ، السعودية . 1 الهباهبة ، هارون ( 1999 ) : تقييم الحاجات الإدارية والفنية لمديري المدارس الربادية في الأردن ، رسالة ماجستير غير منشورة ،

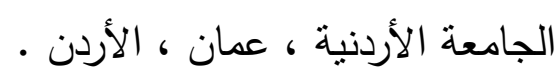

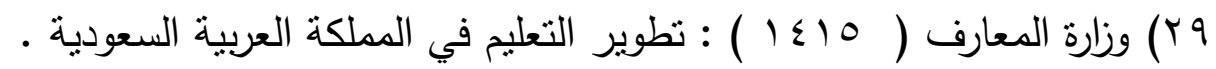
وزارة المعارف ( • ـ ا ) : القواعد المنظمة لمدارس التعليم العام في المملكة العربية السعودية ـ الطبعة الأولى. 